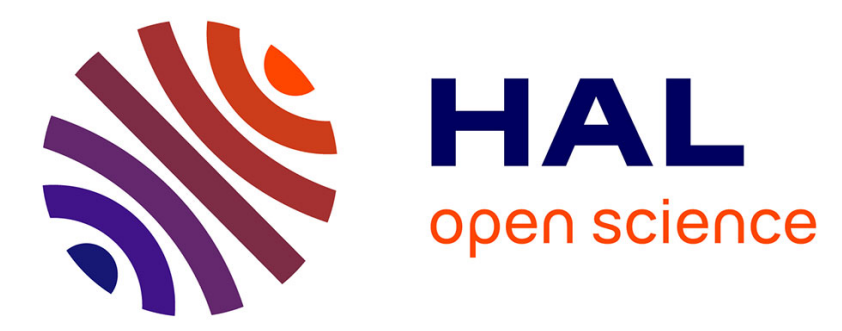

\title{
Genetic basis of semen traits and their relationship with growth rate in rabbits
}

Llibertat Tusell, Andres Legarra, M. Garcia-Tomas, O. Rafel, J. Ramon, M. Piles

\section{- To cite this version:}

Llibertat Tusell, Andres Legarra, M. Garcia-Tomas, O. Rafel, J. Ramon, et al.. Genetic basis of semen traits and their relationship with growth rate in rabbits. Journal of Animal Science, 2012, 90 (5), pp.1385-1397. 10.2527/jas.2011-4165 . hal-02652206

\section{HAL Id: hal-02652206 https: / hal.inrae.fr/hal-02652206}

Submitted on 29 May 2020

HAL is a multi-disciplinary open access archive for the deposit and dissemination of scientific research documents, whether they are published or not. The documents may come from teaching and research institutions in France or abroad, or from public or private research centers.
L'archive ouverte pluridisciplinaire HAL, est destinée au dépôt et à la diffusion de documents scientifiques de niveau recherche, publiés ou non, émanant des établissements d'enseignement et de recherche français ou étrangers, des laboratoires publics ou privés. 


\section{JOURNAL OF ANIMAL SCIENCE}

The Premier Journal and Leading Source of New Knowledge and Perspective in Animal Science

Genetic basis of semen traits and their relationship with growth rate in rabbits

L. Tusell, A. Legarra, M. García-Tomás, O. Rafel, J. Ramon and M. Piles

J ANIM SCI 2012, 90:1385-1397.

doi: 10.2527/jas.2011-4165 originally published online November 18, 2011

The online version of this article, along with updated information and services, is located on the World Wide Web at:

http://www.journalofanimalscience.org/content/90/5/1385

WWw.asas.org 


\title{
Genetic basis of semen traits and their relationship with growth rate in rabbits ${ }^{1}$
}

\author{
L. Tusell,*2 A. Legarra, $†$ M. García-Tomás,* O. Rafel,* J. Ramon,* and M. Piles* \\ *Unitat de Cunicultura, Institut de Recerca i Tecnologia Agroalimentàries, Torre Marimon s/n, 08140, Caldes de Montbui, \\ Barcelona, Spain; and †INRA UR 631 Station d'Améloration Génétique des Animaux, 31320, Castanet-Tolosan, France
}

\begin{abstract}
This work aims to estimate the genetic parameters of seminal and production traits in a paternal line of rabbits selected for ADG during the fattening period. The considered traits were male libido (Lib) defined as successful mounting of an artificial vagina; presence of urine (Ur) and calcium carbonate deposits $(\mathrm{Ca})$ in the ejaculate; semen $\mathrm{pH}$; individual sperm motility (IM); the suitability for AI of the ejaculate (Sui), which involves the subjective combination of several quality traits; the average ejaculate volume (Vol); sperm concentration (Conc); and the average sperm production per ejaculate $(\mathrm{Prod}=\mathrm{Vol} \times \mathrm{Conc})$. The genetic relationship between all of these traits with ADG is also provided. Male libido and seminal data came either from routine evaluations of the ejaculates in an AI center or from 2 experiments in which bucks from the same population were used. Two consecutive ejaculates per male and per week were collected, leaving $7 \mathrm{~d}$ within weekly collections. A linear tri-trait model was used to analyze Conc, Vol, and ADG, whereas linear and threshold-linear 2-trait models were used to analyze male libido and the remaining seminal traits with ADG. A Bayesian approach was adopted for inference.
\end{abstract}

Approximately $38 \%$ of ejaculates were rejected for AI primarily due to low IM scores. Variables related to the quality of the ejaculate (Ur, Ca, $\mathrm{pH}, \mathrm{IM}$, Sui) and $\mathrm{Lib}$ were found to be lowly heritable $\left(\mathrm{h}^{2}\right.$ ranged from 0.04 to 0.11 ), but repeatable. This indicates performance of bucks for seminal quality traits and libido in AI centers would be more strongly affected by management practices rather than genetic selection. Semen production traits exhibited moderate values of $h^{2}(0.22,0.27$, and 0.23 for Conc, Vol, and Prod, respectively), suggesting the possibility of effective selection for these traits. A moderate to high negative genetic correlation $\left(\mathrm{r}_{\mathrm{g}}\right.$; posterior mean; highest posterior density at $95 \%$, $\left.\mathrm{HPD}_{95 \%}\right)$ was estimated between Conc and Vol $(-0.53$, $\left.\mathrm{HPD}_{95 \%}=-0.76,-0.27\right)$. The ADG was estimated to have an $\mathrm{h}^{2}$ of 0.16 , to have a low, positive $\mathrm{r}_{\mathrm{g}}$ with Conc $\left(0.21, \mathrm{HPD}_{95 \%}=-0.03,0.48\right)$, to have a low, negative $r_{g}$ with $\operatorname{Vol}\left(-0.19, \mathrm{HPD}_{95 \%}=-0.47,0.08\right)$, and to be genetically uncorrelated with all remaining traits analyzed. Therefore, selection for increasing ADG in paternal lines is expected to have no detrimental effects on $\mathrm{Ur}, \mathrm{Ca}, \mathrm{pH}, \mathrm{IM}$, Sui, and Lib and little to no effect on Conc, Vol, and Prod.

Keywords: ejaculate quality, genetic parameter, growth, semen production, rabbit

(C) American Society of Animal Science. All rights reserved.

J. Anim. Sci. 2012.90:1385-1397

doi:10.2527/jas2011-4165

\section{INTRODUCTION}

\footnotetext{
${ }^{1}$ This research was supported by the Instituto Nacional de Investigación y Tecnología Agraria y Alimentaria (INIA, Madrid, Spain) project RTA2005-00088-CO2. Part of it was carried out during a visit of the first author to INRA UR 631 Station d'Amélioration Génétique des Animaux (Castanet-Tolosan, France). Project partly supported by Toulouse Midi-Pyrénées bioinformatic platform (Toulouse, France). Llibertat Tusell Palomero received a fellowship from the INIA. The authors are grateful to the staff of Unitat de Cunicultura, IRTA (Caldes de Montbui, Barcelona, Spain) for their invaluable cooperation and Jamie Williams (Eolia, MO) for the suggestions and the English revision of the manuscript.

${ }^{2}$ Corresponding author: 1libertat.tusell@gmail.com

Received April 12, 2011.

Accepted November 14, 2011.
}

Terminal bucks used for AI come from lines exclusively selected for growth traits (Baselga, 2004). Although they have good genetic merit for growth and feed efficiency, no attention is placed on their reproductive performance and seminal characteristics. However, bucks used to produce doses to inseminate in commercial farms should also have good semen production and quality to potentially produce a large number of fertile doses. Optimal reproductive results are achieved with commercial AI in rabbits (e.g., $80.5 \%$ of conception rate and 10.34 number of total kits born per 
litter were obtained on average in French rabbit farms; ITAVI, 2008), largely because the procedures used for AI in rabbits aim to maximize the probability of fertilization of oocytes. However, efficiency of the AI centers seems to be far from optimal: the production and characteristics of semen are highly variable between collections (García-Tomás et al., 2006c), the ejaculate rejection rate in AI centers is large (38 to $52 \%$; Brun et al., 2002a; Theau-Clément et al., 2003), and lack of libido and infertility are the most important causes for culling males in rabbit farms (Rosell and de la Fuente, 2009).

To examine the possibility of genetic improvement for increasing AI dose production per buck, this work aims to estimate the genetic parameters of the following seminal and production traits: male libido, defined as successful mounting to an artificial vagina; presence of urine and calcium carbonate deposits in the ejaculate; semen $\mathrm{pH}$; individual sperm motility; the suitability for AI of the ejaculate, which involves the subjective combination of several quality traits; the average ejaculate volume; sperm concentration; and the average sperm production per ejaculate. Additionally, genetic correlations between each semen characteristic with ADG were estimated to determine if selection for growth would have a correlated effect on male semen production and quality.

\section{MATERIALS AND METHODS}

The research protocol was approved by the Animal Care and Use Committee of the Institut de Recerca $\mathrm{i}$ Tecnologia Agroalimentàries.

\section{Management}

Bucks belonged to the Caldes line, which is selected for growth rate during the fattening period. They were bred and reared in the nucleus of selection in Caldes de Montbui (Barcelona, Spain). This farm has insulated roof and walls and cooling equipment to avoid animal exposure to extreme temperatures [e.g., the average temperature (SD) of the whole period in which the seminal data was collected was $\left.19.5^{\circ} \mathrm{C}(3.04)\right]$. After weaning at $32 \mathrm{~d}$, males were housed in cages of 8 individuals with a photoperiod of $16 \mathrm{~h}$ of light/d. Animals were fed a commercial diet ad libitum (15.5\% CP, 2.3\% fat, 17.2\% fiber) until d 60. Average daily gain was measured during the fattening period (from 32 to $60 \mathrm{~d}$ old). After the fattening period, animals were individually housed and their feed was restricted to $180 \mathrm{~g} / \mathrm{d}$ of another commercial diet ( $16 \%$ CP, $4.3 \%$ fat, $17 \%$ fiber). Fresh water was always available.

Good health status (i.e., animals were free from illness, injury, or pain) was the sole criterion used for selecting young bucks to be used both in the AI center and in the experimental studies where males were evaluated for seminal production traits.

Selected males were trained at 4.5 mo of age to use an artificial vagina for ejaculate collection. A homemade polyvinyl chloride artificial vagina containing water at a temperature of $50^{\circ} \mathrm{C}$ was used. For ejaculate collection, the artificial vagina was hand-held beneath a doe with the open end pointed in a caudal direction and together they were placed inside the cage of the buck to allow the male to mount the doe. As the buck began to mount, penetration of the male penis into the artificial vagina was allowed and the ejaculate was collected in a tube connected to the artificial vagina (for further details of the procedure, refer to Morrell, 1995). To train young males to use an artificial vagina for ejaculate collection, bucks were solicited for ejaculate collection once a week for the first $2 \mathrm{wk}$. At 5 mo of age, males were considered sexually mature, bucks were solicited for ejaculate collection 2 times each week with an interval of $30 \mathrm{~min}$ between solicitations within a week. The time period between male solicitations to ejaculate collection of 2 consecutive weeks was $7 \mathrm{~d}$. Semen data analyzed in this study are from sexually mature males.

\section{Male Libido and Seminal Trait Data}

All data used were collected in the IRTA AI center from routine evaluations to prepare AI commercial doses as well as specific experimental periods in which extra seminal measurements were collected. Male libido (sexual desire) was recorded as a binary trait ( $\mathbf{L i b}=1$ if male successfully mounted; i.e., if male showed signs of falling off the doe when mating; 0 otherwise). Visual detection was used to identify and discard for further evaluation ejaculates contaminated with urine ( $\mathbf{U r}$, assessed by the yellowish color of the semen instead of the typically translucent with white, gray color), calcium carbonate deposits (Ca, assessed by the presence of sandy sediments in the ejaculate), and blood (assessed by the pink or reddish color of the semen). Both the Ur and Ca traits were defined as binary: $1=$ presence, $0=$ absence. All gel plugs were removed. Ejaculates were stored at $37^{\circ} \mathrm{C}$ and were evaluated within $15 \mathrm{~min}$ after collection. The $\mathrm{pH}$ of the ejaculate was determined using a 507 Crison pH-meter (Crison Instruments, S.A., Alella, Barcelona, Spain). Ejaculate volume was determined using either a graduate tube or a micro-pipette.

Ejaculates were diluted 1:4 (vol/vol) in a commercial extender (Galap, IMV Technologies, Saint Ouen sur Iton, France). Aliquots $(25 \mu \mathrm{L})$ were evaluated under a microscope with a phase-contrast optic (Nikon, Lewisville, TX) at $400 \times$ magnification to assess individual sperm motility (IM). The IM of each sample was recorded and analyzed on a subjective scale that ranged from 0 to 5, which cor- 
responded to a percentage of sperm showing progressive movement: 0 to 10,11 to 25,26 to 50,51 to 70,71 to 90 , or 91 to $100 \%$, respectively (Roca et al., 2000).

The suitability for AI of the ejaculate (Sui) was defined as a binary trait $(1=$ suitable, $0=$ unsuitable for $\mathrm{AI})$ and was assessed subjectively by a technician. An ejaculate was considered unsuitable for $\mathrm{AI}$ if presented any of the following characteristics: presence of Ur, blood, and $\mathrm{Ca}$ in the ejaculate, an IM score $\leq 2$, the presence of a large number (approximately $>50 \%$ ) of dead spermatozoa, and the presence of clustered spermatozoa (both assessed by visual detection under microscope). Because an ejaculate could present more than one characteristic of unsuitability for AI, it could be discarded for AI for more than one reason at the same time.

Seminal data of Lib, Ur, Ca, IM, and Sui came from routine evaluations performed in the IRTA AI center from December 2001 to December 2009. Within this period, data of semen $\mathrm{pH}$, ejaculate volume, and sperm concentration were collected in the same AI center in 2 experimental periods: January 2002 to December 2002 and January 2006 to September 2007. In the first experimental period, sperm concentration was measured in each ejaculate using a Thoma Zeiss counting cell chamber. The analyzed trait was the sperm concentration per male on the day of collection (Conc). In cases where there were 2 ejaculates suitable for AI per male on a given day, Conc was calculated as $\left(\mathrm{Conc}_{1} \times \mathrm{Vol}_{1}+\mathrm{Conc}_{2} \times \mathrm{Vol}_{2}\right) /\left(\mathrm{Vol}_{1}+\right.$ $\mathrm{Vol}_{2}$ ), where subscripts 1 and 2 are the first and second ejaculate of the male on the day of ejaculate collection. In the second experimental period, Conc was measured using a counter of sperm cells (NucleoCounter SP-100, ChemoMetec A/S, Allerod, Denmark) after pooling semen from both suitable ejaculates for AI obtained from the same buck on the same day. No differences in Conc measurements have previously been encountered using either a hemocytometer or the Nucleocounter SP100 (Theau-Clément and Falières, 2005).

The average ejaculate volume per male each day (Vol) was calculated as $\left(\mathrm{Vol}_{1}+\mathrm{Vol}_{2} / \mathrm{n}\right)$, where $\mathrm{n}$ is the total number of ejaculates obtained per male on the day of collection $(\mathrm{n}=1,2)$. Collections in which the male successfully mounted the doe but no ejaculate was collected in the collection tube were considered as $\mathrm{Vol}=0$ $\mathrm{mL}$. Whenever a nonzero Vol was obtained, the average sperm production per ejaculate (Prod) was determined by multiplying Vol by Conc.

Seminal traits Lib, Ur, Ca, IM, and Sui involved 883 males from approximately 740 litters, whereas pH, Vol, Conc, and Prod involved 541 males from approximately 470 litters. Total numbers of records obtained for each seminal trait are presented in Table 1. There were a total of 118,306 records of ADG, which correspond to all the data from the foundation of the line. The pedigree included 118,574 animals.

\section{Model and Statistical Analysis}

The seminal traits Lib, Ur, Ca, pH, IM, Prod, and Sui were each analyzed with ADG in a bivariate analysis to avoid selection bias in the estimates of the (co) variance components and to determine the relationship between ADG and the seminal traits. The Vol and Conc were analyzed jointly with ADG in a trivariate analysis to estimate the correlations among the 3 traits. Models were Gaussian for the continuous traits $\mathrm{pH}$, IM, Vol, Conc, Prod, and ADG, whereas threshold models were used to analyze the binary traits Lib, Ur, Ca, and Sui. In this study, a multivariate analysis including all seminal traits and ADG was not attempted because not enough data of the seminal traits were available to allow the estimation of the increased number of parameters of the resultant model.

The threshold model assumes the observed binary responses are indicators of an underlying continuous random variable ( $\boldsymbol{l}$; liability; Falconer, 1965) and a fixed threshold, which divides the continuous scale into 2 intervals and forms the 2 response categories (Wright, 1934).

Table 1. Summary statistics of ADG and seminal traits expressed as average percentage per buck.

\begin{tabular}{lcrccc}
\hline Trait & Minimum & Mean & Maximum & CV & No. of records \\
\hline $\mathrm{ADG}^{1}$ & 10.78 & 45.98 & 88.95 & 0.18 & 118,306 \\
$\mathrm{Lib}^{2}$ & 0 & 0.80 & 1 & 1.58 & 13,914 \\
$\mathrm{Ur}^{3}$ & 0 & 0.08 & 1 & 2.15 & 14,383 \\
$\mathrm{Ca}^{4}$ & 0 & 0.22 & 1 & 1.18 & 14,449 \\
$\mathrm{pH}^{5}$ & 6.35 & 7.45 & 8.66 & 0.05 & 1,386 \\
$\mathrm{IM}^{6}$ & 0 & 2.69 & 4.67 & 0.28 & 13,727 \\
$\mathrm{Sui}^{7}$ & 0 & 0.61 & 1 & 0.50 & 14,240 \\
$\mathrm{Conc}^{8}$ & 0 & 331.82 & $1,616.04$ & 0.67 & 1,290 \\
Vol $^{9}$ & 0.07 & 0.77 & 2.1 & 0.53 & 1,225 \\
Prod $^{10}$ & 29.875 & 670.83 & $2,450.50$ & 0.49 & 1,077 \\
\hline
\end{tabular}

${ }^{1} \mathrm{ADG}=\mathrm{ADG}$ during the fattening period $(\mathrm{g} / \mathrm{d})$.

${ }^{2} \mathrm{Lib}=$ male libido (binary trait: $1=$ success to mount artificial vagina, $0=$ failure).

${ }^{3} \mathrm{Ur}=$ presence of urine in the ejaculate (binary trait: $1=$ presence, $0=$ absence).

${ }^{4} \mathrm{Ca}=$ presence of calcium carbonate deposits in the ejaculate (binary trait: $1=$ presence, $0=$ absence).

${ }^{5} \mathrm{pH}=\mathrm{pH}$ of the ejaculate.

${ }^{6} \mathrm{IM}=$ individual sperm motility (subjective scale from 0 to 5 corresponding to a percentage of sperm showing progressive movement of 0 to 10,11 to 25 , 26 to 50,51 to 70,71 to 90 , or 91 to $100 \%$, respectively).

${ }^{7}$ Sui $=$ ejaculate suitability for AI (binary trait: $1=$ suitable, $0=$ unsuitable).

${ }^{8} \mathrm{Conc}=$ average sperm concentration of the ejaculate per male on the day of collection $\left(\times 10^{6}\right.$ spermatozoa $\left./ \mathrm{mL}\right)$.

${ }^{9} \mathrm{Vol}=$ average volume of the ejaculate per male on the day of collection $(\mathrm{mL})$.

${ }^{10}$ Prod $=$ average sperm production per ejaculate $\left(\times 10^{6}\right.$ spermatozoa $)$. 
The general model assumed for the analysis of the seminal traits was

$$
\mathbf{y}_{s}=\mathbf{X}_{s} \boldsymbol{\beta}_{s}+\mathbf{Z}_{s} \mathbf{u}_{s}+\mathbf{W}_{1, s} \mathbf{p}_{s}+\mathbf{W}_{2, s} \mathbf{c}_{s}+\mathbf{e}_{s},
$$

where $\mathbf{y}_{S}$ is a vector of data for the corresponding continuous seminal traits ( $s=\mathrm{pH}, \mathrm{IM}, \mathrm{Vol}$, Conc, Prod) or a vector of liabilities corresponding to the binary seminal traits ( $s=\mathrm{Lib}, \mathrm{Ur}, \mathrm{Ca}$, and Sui), $\beta_{s}$ is a vector of systematic effects, $\mathbf{u}_{S}$ is a vector of additive genetic effects, $\mathbf{p}_{s}$ is a vector of random permanent environmental effects, $\mathbf{c}_{s}$ is a vector of common litter environmental effects, and $\mathbf{e}_{s}$ is a vector of residuals. Terms $\mathbf{X}_{s}, \mathbf{Z}_{s}, \mathbf{W}_{1, s}$, and $\mathbf{W}_{2, s}$ are incidence matrices relating data with the systematic, random genetic, random permanent environmental effects, and common litter environmental effects, respectively. The systematic effects included in the model were order of the ejaculate ( 2 levels, first or second; this effect was not included in Vol, Conc, and Prod models), year-season of collection (2-mo intervals: 33 levels for Lib, Ur, Ca, IM, and Sui, and 13 levels for $\mathrm{pH}, \mathrm{Vol}, \mathrm{Conc}$, and Prod), and male age (7 levels for Lib, Ur, Ca, IM, and Sui: 4 to $6,>6$ to $8,>8$ to $10,>10$ to 12 , $>12$ to $16,>16$ to $24,>20$ mo and 3 levels for $\mathrm{pH}$, Vol, Conc, and Prod: 4 to $6,>6$ to $8,>8$ to $10 \mathrm{mo}$ ).

The following model was assumed for ADG:

$$
\begin{aligned}
& \mathbf{y}_{a d g}=\mathbf{X}_{a d g} \boldsymbol{\beta}_{a d g}+\mathbf{Z}_{a d g} \mathbf{u}_{a d g} \\
& +\mathbf{W}_{1, a d g} \mathbf{p}_{a d g}+\mathbf{W}_{2, a d g} \mathbf{c}_{a d g}+\mathbf{e}_{a d g},
\end{aligned}
$$

where $\mathbf{y}_{a d g}$ is a vector of ADG measurements, $\beta_{a d g}$ is a vector of systematic effects of ADG, $\mathbf{u}_{a d g}$ and $\mathbf{c}_{a d g}$ correspond to the same effects as those defined for seminal traits in the previous model. Because seminal traits and ADG were collected at 2 different time periods in the lifetime of a given buck and different records of seminal traits and male libido corresponded to only 1 ADG record, the residual $\left(\mathbf{e}^{*}\right)$ was decomposed into 2 residual terms: $\mathbf{e}^{*}=\mathbf{p}_{a d g}+\mathbf{e}_{a d g}$, where $\mathbf{p}_{a d g}$ relates to the male permanent environmental effect of the corresponding seminal trait. This decomposition of the residual was carried out to increase data connectivity and to allow for estimation of a possible environmental correlation between ADG and each seminal trait and male libido. Covariance between $\mathbf{p}_{a d g}$ and $\mathbf{p}_{s}$ can be estimated because there are repeated measures of the seminal traits and male libido, and therefore variance of $\mathbf{p}_{s}$ can be estimated. Incidence matrices $\mathbf{X}_{a d g}, \mathbf{Z}_{a d g}, \mathbf{W}_{1, a d g}$, and $\mathbf{W}_{2, a d g}$ relate growth data with the systematic, random genetic, random permanent environmental, and common litter environmental effects, respectively. The systematic effects included in the ADG model were yearseason of birth (105 levels), parity order (6 levels: 1, $\ldots, 5,>5$ parities), and number of kits born alive in the litter to which the individual was born ( 8 levels: $\leq 5,6$, $\ldots, 11, \geq 12$ kits born alive).

A Bayesian framework was adopted for inference. Denote $\boldsymbol{\Omega}=\{\boldsymbol{\beta}, \mathbf{u}, \mathbf{p}, \mathbf{c}, \mathbf{G}, \mathbf{P}, \mathbf{C}, \mathbf{R}\}$ as the vector including all the unknown parameters in the model, where $\boldsymbol{\beta}^{\prime}=\left(\boldsymbol{\beta}_{s}^{\prime}, \boldsymbol{\beta}_{a d g}^{\prime}\right), \mathbf{u}^{\prime}=\left(\mathbf{u}_{s}^{\prime}, \mathbf{u}_{a d g}^{\prime}\right), \mathbf{p}^{\prime}=\left(\mathbf{p}_{s}^{\prime}, \mathbf{p}_{a d g}^{\prime}\right)$, and $\mathbf{c}^{\prime}=\left(\mathbf{c}_{s}^{\prime}, \mathbf{c}_{a d g}^{\prime}\right)$. The terms $\mathbf{G}, \mathbf{P}, \mathbf{C}$ are the different (co) variance matrices of the corresponding random effects defined above, and $\mathbf{R}$ is the residual (co)variance matrix. The joint posterior distribution of all parameters for the joint analyses of 2 continuous traits was

$$
p\left(\boldsymbol{\Omega} \mid \mathbf{y}_{s}, \mathbf{y}_{a d g}\right) \propto p\left(\mathbf{y}_{s}, \mathbf{y}_{a d g} \mid \boldsymbol{\Omega}\right) \times p(\boldsymbol{\Omega}),
$$

whereas the joint posterior distribution of all parameters for the analysis of a categorical and a continuous trait was

$$
p\left(\boldsymbol{\Omega}, \mathbf{l} \mid \mathbf{y}_{a d g}, \mathbf{y}_{s}\right) \propto p\left(\mathbf{y}_{a d g}, \mathbf{l} \mid \boldsymbol{\Omega}\right) \times p\left(\mathbf{y}_{s} \mid \mathbf{l}, \boldsymbol{\Omega}\right) \times p(\boldsymbol{\Omega}) .
$$

The assigned prior distributions for the parameters of the models were

$$
\begin{aligned}
& p(\boldsymbol{\beta}) \sim k p\left(\mathbf{u}_{m} \mid \mathbf{G}\right) \sim N(\mathbf{0}, \mathbf{G} \otimes \mathbf{A}) \\
& p(\mathbf{p} \mid \mathbf{P}) \sim N(\mathbf{0}, \mathbf{P} \otimes \mathbf{I}) p(\mathbf{c} \mid \mathbf{C}) \sim N(\mathbf{0}, \mathbf{C} \otimes \mathbf{I}),
\end{aligned}
$$

where $k$ is a constant and $\mathbf{A}$ is the numerator relationship matrix of all the individuals. Bounded uniform prior distributions were assumed for $\beta$ and the components of $\mathbf{G}, \mathbf{P}$, and $\mathbf{C}$. For the binary traits, the threshold and the residual variance were fixed to 0 and 1 , respectively.

For the continuous traits, the prior distribution for the residuals was $p(\mathbf{e} \mid \mathbf{R}) \sim N(\mathbf{0}, \mathbf{R} \otimes \mathbf{I})$, and bounded uniform priors were assumed for the elements of $\mathbf{R}$.

The off-diagonal elements of $\mathbf{R}$ were always set to zero except in the trivariate analyses, where the elements corresponding to the residual covariance between Vol and Conc were estimated.

The marginal posterior distributions of the parameters of interest were derived from the joint posterior density of all the unknowns. The Gibbs sampler algorithm was used to estimate the marginal posterior distributions of the systematic effects and the (co)variance components using the TM software developed by Legarra et al. (2008). Conditional distributions of the model parameters, necessary for the implementation of this algorithm, can be found in Sorensen and Gianola (2002). Single chains of $1,000,000$ and 3,000,000 iterations were run discarding the first 250,000 and 1,000,000 iterations of each chain in the bivariate and trivariate analyses, respectively. Samples of the parameters of interest were saved every 100 rounds. The number of discarded samples was, in all cases, much larger than the required burn-in determined by the procedures of Raftery and 
Lewis (1992) and Geweke (1992). The sampling variance of the chains was obtained by computing Monte Carlo SE (Geyer, 1992). Summary statistics from the marginal posterior distributions were calculated directly from the samples saved.

\section{RESULTS AND DISCUSSION}

\section{Summary Statistics of $A D G$ and Seminal Traits}

Summary statistics for the seminal traits and ADG expressed as average percentage per buck are shown in Table 1. Means of the different seminal traits were within the range of values obtained for rabbits in previous studies reviewed by Alvariño (2000). The mean of ADG was also in accordance with those obtained in other rabbit lines (Vogt, 1979; Moura et al., 1997; Lavara et al., 2011). A large portion of the seminal and Lib data came from routine evaluations performed in the AI center to prepare AI commercial doses; therefore, it is possible that there is some bias associated with these raw means. This potential for bias stems from the selection strategy followed by this AI center in which bucks are replaced based upon a lack of libido and poor sperm production. After 3 mo in production, buck replacement is only performed in older bucks, for reasons of lack of libido, poor sperm production and quality, and poor health status, the last being the most common reason for buck culling in the AI center. Because bucks with poor libido and poor sperm production and quality are only replaced after 3 mo in production; presumably this selection strategy will not have a large effect on the estimates of male variance components because enough data are collected per individual.

The percentage of successful collection rate with the artificial vagina was very high and in agreement with the one obtained in previous studies. This result contributes to reflect the high adaptability of this species to be used in AI centers for dose production (Brun et al., 2002a, 2006; Theau-Clément et al., 2003).

However, the efficiency in the use of bucks in AI centers still seems to be less than optimal. A low percentage $(62 \%)$ of ejaculates were considered suitable for AI, and this estimate is in agreement with similar studies performed on rabbits (Brun et al., 2002a, 2006; Theau-Clément et al., 2003; García-Tomás et al., 2006a). These results suggest criteria for ejaculate rejection could be too restrictive or that, in some cases, it could be necessary to improve the qualitative characteristics of the ejaculate through management procedures or genetic selection. Low IM was the main reason for ejaculate rejection in this line (representing a $66 \%$ of total rejections), followed by the presence of $\mathrm{Ca}$ and $\mathrm{Ur}$ in the ejaculates (Figure 1).
Sperm concentration and sperm motility are considered important variables influencing fertility (Castellini and Lattaioli, 1999; Brun et al., 2002b; Lavara et al., 2005; García-Tomás et al., 2006b). For that reason, individual or mass motility score or both are commonly used as criteria for ejaculate rejection in most AI centers. Conversely, individual sperm concentration is not commonly evaluated in rabbits because pooling ejaculates from several bucks is a common practice in rabbit AI centers. Thus, sperm concentration is only measured in the pooled ejaculate to perform the proper dilution to reach the standardized concentration of a heterospermic commercial dose.

Presence of Ur in the ejaculate has been found to be one of the principal factors for ejaculate rejection in rabbits (Brun et al., 2002a, 2006; Theau-Clément et al., 2003). Calcium carbonate deposits, which in this line were present in $17 \%$ of ejaculates, are also encountered in the bladder. However, sources of this Ca are still unknown and, to our knowledge, their presence has only been noted in a previous study carried out on the same experimental farm (García-Tomás et al., 2006a). In that study, presence of Ca was observed in another line but at a decreased frequency, indicating there could be differences between lines in the expression of this trait. To optimize the management of the bucks in the AI center, further research should be carried out to establish the origin and causes of the presence of $\mathrm{Ca}$ in the ejaculates. The presence of $\mathrm{Ca}$ in the ejaculates complicates the evaluation of the ejaculate for seminal quality in the laboratory and may have a detrimental effect on reproductive performance.

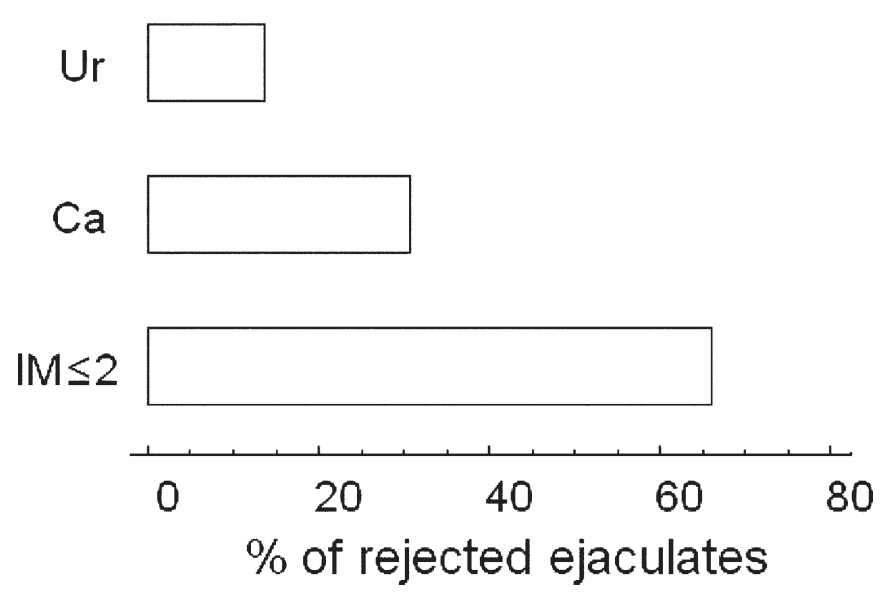

Figure 1. Relative importance of several causes of ejaculate rejection for AI: presence of urine (Ur), presence of calcium carbonate deposits $(\mathrm{Ca})$, and individual motility score less than or equal to $2(\mathrm{IM} \leq 2)$ on a subjective scale from 0 to 5 corresponding to a percentage of sperm showing progressive movement of 0 to 10,11 to 25,26 to 50,51 to 70,71 to 90 , or 91 to $100 \%$, respectively. 
The $\mathrm{pH}$ of the semen was within the range of values obtained in the same line and in other rabbit breeds (Brun et al., 2002b, 2009; García-Tomás et al., 2006a). The $\mathrm{pH}$ could be considered a general semen quality indicator: the greater the concentration and motility of the spermatozoids in the ejaculate, the greater the production of lactic acid due to the greater metabolic activity and the lower the $\mathrm{pH}$ (Coffey, 1988; Brun et al., 2009). As a consequence, the value of this trait lies in its relationship with fertility: the lower $\mathrm{pH}$ class corresponded to the greater kindling rate in Brun et al. (2002b); and a negative and almost linear effect of $\mathrm{pH}$ on fertility was denoted by Tusell et al. (2011) when they analyzed the relationship of these 2 traits using recursive or classical univariate or bivariate models. Because semen $\mathrm{pH}$ is not expensive to measure, it could be of interest to include semen $\mathrm{pH}$ in routine measurements of the AI centers to select ejaculates to be used for AI to improve both conception rates and the selection of the most fertile males to use in the AI centers.

\section{(Co)Variance Component Estimates}

Table 2 shows features of the estimated marginal posterior distributions (EMPD) corresponding to the ratios between variance components and phenotypic variances for ADG and the seminal traits. Parameter estimates of the effects included in the ADG model did not change among the analyses. Therefore, for simplicity, only ADG estimates obtained in one of the models are presented (bivariate model with ADG and Lib). The heritability $\left(\mathbf{h}^{2}\right)$ for ADG was in accordance with estimates from previous studies obtained in other rabbit lines (Larzul and Gondret, 2005; Lavara et al., 2011) and in the same line (Piles et al., 2004).

Seminal traits showed low to moderate values of $h^{2}$ and repeatability (r; calculated as the sum of the $h^{2}$ and the ratios of variance of permanent and common litter environmental effects). The ratios of variance of the permanent environmental effects ranged from 0.07 to 0.18 for all the seminal traits. The proportion of variance due to the common litter effect was almost null for the seminal traits, whereas it represented a high proportion of the total phenotypic variance for ADG in agreement with results obtained by Lavara et al. (2011) and Piles et al. (2004).

\section{Male Lib and Presence of $U r$ and $C a$ in the Ejaculate}

Traits Lib, Ur, and $\mathrm{Ca}$ were found to be lowly heritable, which could be attributed in part to the great variability inherent in these traits due to factors involved in semen collection (i.e., variation in the temperature of the artificial vagina that could lead to a greater presence of
Ur and $\mathrm{Ca}$ in the ejaculate or unsuccessful mountings; Morrell, 1995). Therefore, genetic selection for increasing semen production by improving Lib and reducing

Table 2. Mean (highest posterior density interval at 95\% in brackets, and Monte Carlo SE in parentheses) of the marginal distribution of heritability $\left(\mathrm{h}^{2}\right)$, phenotypic variance $\left(\sigma^{2}\right)$, ratio of variance of male permanent $(\mathrm{pm})$ and common litter (c) environmental effects to phenotypic variance for ADG and seminal traits.

\begin{tabular}{|c|c|c|c|c|}
\hline \multirow[b]{2}{*}{ Trait } & \multicolumn{4}{|c|}{ Parameter } \\
\hline & $\mathrm{h}^{2}$ & $\mathrm{pm}$ & $\mathrm{c}$ & $\sigma^{2}$ \\
\hline \multirow[t]{3}{*}{$\overline{\mathrm{ADG}^{1}}$} & 0.16 & 0.27 & 0.29 & 52.17 \\
\hline & {$[0.14,0.18]$} & {$[0.13,0.44]$} & {$[0.28,0.30]$} & {$[51.49,52.82]$} \\
\hline & $(0.001)$ & $(0.011)$ & $(0.000)$ & $(0.015)$ \\
\hline \multirow[t]{3}{*}{$\mathrm{Lib}^{2,3}$} & 0.06 & 0.10 & 0.04 & 1.24 \\
\hline & {$[0.03,0.09]$} & {$[0.05,0.14]$} & {$[0.00,0.08]$} & {$[1.20,1.28]$} \\
\hline & $(0.002)$ & $(0.003)$ & $(0.003)$ & $(0.001)$ \\
\hline \multirow[t]{3}{*}{$\mathrm{Ur}^{3,4}$} & 0.04 & 0.07 & 0.02 & 1.15 \\
\hline & {$[0.02,0.07]$} & {$[0.04,0.10]$} & {$[0.00,0.04]$} & {$[1.12,1.18]$} \\
\hline & $(0.002)$ & $(0.002)$ & $(0.001)$ & $(0.001)$ \\
\hline \multirow[t]{3}{*}{$\mathrm{Ca}^{3,5}$} & 0.08 & 0.11 & 0.02 & 1.27 \\
\hline & {$[0.04,0.12]$} & {$[0.08,0.15]$} & {$[0.00,0.04]$} & {$[1.24,1.31]$} \\
\hline & $(0.003)$ & $(0.002)$ & $(0.001)$ & $(0.001)$ \\
\hline \multirow[t]{3}{*}{$\mathrm{pH}^{6}$} & 0.11 & 0.18 & 0.03 & 0.23 \\
\hline & {$[0.05,0.18]$} & {$[0.11,0.25]$} & {$[0.00,0.06]$} & {$[0.21,0.26]$} \\
\hline & $(0.005)$ & $(0.004)$ & $(0.002)$ & $(0.001)$ \\
\hline \multirow[t]{3}{*}{$\mathrm{IM}^{7}$} & 0.08 & 0.14 & 0.02 & 1.16 \\
\hline & {$[0.04,0.13]$} & {$[0.10,0.19]$} & {$[0.00,0.05]$} & {$[1.12,1.21]$} \\
\hline & $(0.003)$ & $(0.002)$ & $(0.001)$ & $(0.001)$ \\
\hline \multirow[t]{3}{*}{$\mathrm{Sui}^{3,8}$} & 0.06 & 0.12 & 0.02 & 1.25 \\
\hline & {$[0.03,0.09]$} & {$[0.08,0.15]$} & {$[0.00,0.05]$} & {$[1.22,1.29]$} \\
\hline & $(0.002)$ & $(0.002)$ & $(0.001)$ & $(0.001)$ \\
\hline \multirow[t]{3}{*}{ Conc $^{9}$} & 0.27 & 0.17 & 0.05 & $57,459.38$ \\
\hline & {$[0.14,0.31]$} & {$[0.09,0.25]$} & {$[0.01,0.11]$} & {$[51,263.54,63,775.80]$} \\
\hline & $(0.005)$ & $(0.004)$ & $(0.003)$ & $(193.05)$ \\
\hline \multirow[t]{3}{*}{$\mathrm{Vol}^{10}$} & 0.23 & 0.18 & 0.06 & 0.21 \\
\hline & {$[0.14,0.31]$} & {$[0.09,0.26]$} & {$[0.01,0.11]$} & {$[0.19,0.23]$} \\
\hline & $(0.004)$ & $(0.004)$ & $(0.002)$ & $(0.000)$ \\
\hline \multirow[t]{3}{*}{ Prod $^{11}$} & 0.23 & 0.15 & 0.05 & $134,269.6$ \\
\hline & {$[0.13,0.32]$} & {$[0.06,0.23]$} & {$[0.01,0.10]$} & {$[120,109.75,148,660.45]$} \\
\hline & $(0.005)$ & $(0.005)$ & $(0.002)$ & $(465.94)$ \\
\hline
\end{tabular}

${ }^{1} \mathrm{ADG}=\mathrm{ADG}$ during the fattening period $(\mathrm{g} / \mathrm{d})$.

${ }^{2} \mathrm{Lib}=$ male libido (binary trait: $1=$ success to mount artificial vagina, $0=$ failure).

${ }^{3}$ Estimates of the binary traits $\mathrm{Lib}, \mathrm{Ur}, \mathrm{Ca}$, and Sui are given in the liability scale.

${ }^{4} \mathrm{Ur}=$ presence of urine in the ejaculate (binary trait: $1=$ presence, $0=$ absence).

${ }^{5} \mathrm{Ca}=$ presence of calcium carbonate deposits in the ejaculate (binary trait: $1=$ presence, $0=$ absence) .

${ }^{6} \mathrm{pH}=\mathrm{pH}$ of the ejaculate.

${ }^{7} \mathrm{IM}=$ individual sperm motility (subjective scale from 0 to 5 corresponding to a percentage of sperm showing progressive movement of 0 to 10,11 to 25 , 26 to 50,51 to 70,71 to 90 , or 91 to $100 \%$, respectively).

${ }^{8}$ Sui = ejaculate suitability for AI (binary trait: 1 = suitable, 0 = unsuitable).

${ }^{9} \mathrm{Conc}=$ average sperm concentration of the ejaculate per male on the day of collection $\left(\times 10^{6}\right.$ spermatozoa $\left./ \mathrm{mL}\right)$

${ }^{10} \mathrm{Vol}=$ average volume of the ejaculate per male on the day of collection $(\mathrm{mL})$.

${ }^{11} \mathrm{Prod}=$ the average sperm production per ejaculate $\left(\times 10^{6}\right.$ spermatozoa $)$. 
the number of rejected ejaculates may not be effective. To our knowledge, there is no information in the literature concerning $\mathrm{h}^{2}$ for presence of $\mathrm{Ur}$ and $\mathrm{Ca}$ in the ejaculates. Classifying Lib into 3 categories (no mating, collection after $5 \mathrm{~min}$, and intermediate collection), Panella et al. (1994) reported an $\mathrm{h}^{2}$ of Lib of 0.30 in rabbits. However, results obtained in that work should be taken with caution because all the genetic parameter estimates for seminal traits were unusually high, likely due to the absence in their model of a permanent environmental effect related to the male. Khalil et al. (2007) estimated the $\mathrm{h}^{2}$ of Lib divided into 5 classes (from 1 for low libido to 5 for strong libido) using data from bucks coming from 2 rabbit lines and their reciprocal crosses. Khalil et al. (2007) found a greater estimate for this parameter than the one obtained in our study, due in part to the heterogeneity of the genetic type of the bucks. Flowers (2008) concluded that it would be difficult to improve Lib and mating behaviors in boars through genetic selection due to the low phenotypic variation they observed for these traits in several studies.

The posterior mean (high posterior density interval at 95\%; PM [HPD95\%]) of the repeatability (r) for Ca was $0.21[0.19,0.24]$, indicating a certain stability of the values of this trait over collections of the same male. However, the magnitude of this parameter is not high enough to make decisions concerning buck replacement according to this trait at the beginning of the production period of the male.

\section{Individual Sperm Motility and Suitability for AI of the Ejaculate}

The IM was also found to be lowly heritable and repeatable. The PM [HPD95\%] of $r$ was 0.25 [0.22, $0.28]$. Estimates reported by other authors in rabbits are in agreement with these results for IM or mass motility score (Bencheikh, 1995; Brun et al., 2009) and with the percentage of progressive motility in different breeds of boars (Wolft, 2009) and bulls (Karoui et al., 2011). This low heritability and repeatability could be due in part to the great variability of this trait originating from semen manipulation and time elapsed until evaluation as well as to the subjective manner in which this trait is measured because it is determined by the technician.

The low $\mathrm{h}^{2}$ for Sui is in accordance with the estimate obtained for the subjective semen score used in bulls (Knights et al., 1984), which, in turn, had a high $r_{g}$ with Conc and Vol, perhaps because they were the most important traits taken into consideration for scoring ejaculates. The effect of the technician (Theau-Clément et al., 2009) probably introduces some error to the criterion that determines Sui, decreasing the obtained $\mathrm{h}^{2}$.

\section{Semen $\mathrm{pH}$}

The PM of the $\mathrm{pH} \mathrm{h} \mathrm{h}^{2}$ was similar to the value previously reported in rabbits by Brun et al. (2009) and less than the one obtained in a previous study using a subset of the data analyzed here (0.18; Tusell et al., 2011). The difference between the $\mathrm{h}^{2}$ values obtained with these 2 sets of data could be due to the fact that in the previous study the analyzed trait was the $\mathrm{pH}$ corresponding to the pooled semen obtained from each male on the day of collection. Higher $\mathrm{h}^{2}$ estimates are obtained if traits consist of means (or weighted means) of observations of 2 consecutive measurements or means of several records than if the trait comes from the data of individual records. This fact has been previously denoted for seminal traits by several authors (Ducrocq and Humblot, 1995; Wolft, 2009). The PM (HPD95\%) of repeatability of $\mathrm{pH}$ was 0.33 [0.26, 0.39 ], similar to the value obtained in a previous study where a subset of the data analyzed here was jointly analyzed with data corresponding to bucks from another paternal line and their reciprocal crosses (0.38; GarcíaTomás et al., 2006c).

\section{Sperm Production Traits}

The Conc and Vol traits showed moderate to high values of repeatability (PM [HPD95\%]: 0.48 [0.42, $0.55]$ for Conc and 0.46 [0.40, 0.53] for Vol), indicating the existence of important individual variation for both traits. Similar values were obtained by García-Tomás et al. (2006c). Bencheikh (1995) estimated a repeatability of about 0.38 for Vol and 0.35 for Conc whereas More O'Ferrall and Meacham (1968) obtained a value of 0.29 for Vol, all of them in rabbit.

The $\mathrm{h}^{2}$ for these traits (Conc and Vol) were greater than estimates previously reported in rabbits by Brun et al. (2009) and Lavara et al. (2011) analyzing records from single ejaculates $(0.10$ and 0.08 for Conc, 0.13 and 0.10 for Vol, respectively), whereas the ratios of permanent environmental effects for males were similar. In general, there is a wide range of values of heritability and repeatability of Vol and Conc in different species, varying from extremely low to high values (Robinson and Buhr, 2005), and it is clear that the variation in magnitude found in the literature depends highly upon the definition of the trait (i.e., individual ejaculates or average values).

The EMPD of the genetic, nonadditive genetic plus permanent environmental male effect and phenotypic correlations between Conc and Vol are shown in Figure 2. All the Monte Carlo SE for the estimates of these correlations were less than 0.02 .

The genetic correlation $\left(\mathbf{r}_{\mathbf{g}}\right)$ between Conc and $\mathrm{Vol}$ was moderate and negative (PM: -0.53 ; HPD95\%: $[-0.76,-0.27])$. Several studies also reported similar 
values of this $r_{g}$ in cattle ( -0.4 on average; Ducrocq and Humblot, 1995; Basso et al., 2005), sheep ( -0.36 on average in adult males; Rege et al., 2000; David et al., 2007), goats ( -0.33 on average; Furstoss et al., 2009) and pigs ( -0.60 on average; Smital et al., 2005; Wolf and Smital, 2009). Conversely, Brun et al. (2009) obtained in rabbits an $r_{g}$ between Conc and Vol that could not be considered different from $0(0.38 \pm 0.45)$. Their estimate of the correlation between Conc and Vol did not agree with that in the current study, their negative correlation between permanent environmental effects of the male did $(-0.47 \pm$ 0.14 and PM: -0.51 , HPD95\%: $[-0.78,0.18]$ in Brun et al. (2009) and in our work, respectively). In boars, Smital et al. (2005) also estimated the $r_{g}$ between Conc and Prod (0.21) and between Vol and Prod (0.63), respectively. Smital et al. (2005) obtained an $r_{g}$ between Conc and Vol similar to that in the current study $(-0.61)$, indicating that a greater ejaculate volume does not seem to be associated with a greater number of sperm in the ejaculate that could remain constant or even decrease. Alternatively, the cause of greater concentration of sperm in bull ejaculates seems to be the greater number of sperm, leading to obtain a negative but smaller $r_{g}$ between Conc and Vol because the $r_{g}$ between Conc and Prod and $r_{g}$ between Vol and Prod were 0.60 and 0.66, respectively (Karoui et al., 2011).

Production exhibited a moderate $\mathrm{h}^{2}$ and a moderate to high repeatability (PM [HPD95\%]: 0.42 [0.35, 0.49]), both values being greater than the corresponding values obtained by Lavara et al. (2011) and Brun et al. (2009) for individual ejaculates. The repeatability for Prod was estimated to be 0.33 in previous research by GarcíaTomás et al. (2006c) with both purebred and crossbred bucks. Smital et al. (2005) proposed either total number of spermatozoa or number of insemination doses produced at a certain dosage for developing a composite trait for breeding purposes.

\section{Correlations Between ADG and Seminal Traits}

The EMPD of the genetic, the nonadditive genetic permanent environmental effects, and the phenotypic correlations between ADG and the seminal traits are shown in Figures 3, 4, and 5, respectively. All the Monte Carlo SE for the estimates of these correlations were less than 0.02 .

Selection for increasing ADG would have a favorably correlated response on sperm concentration because the $r_{g}$ (PM [HPD95\%]) between ADG and Conc, although low, was positive $(0.21[-0.03,0.48]$; Figure $3)$. This result is consistent with the low, but negative, $\mathrm{r}_{\mathrm{g}}$ between ADG and $\mathrm{Vol}(-0.19[-0.47,0.08])$; Figure 3). The antagonism between Conc-ADG and Vol-ADG seems to influence the near-zero genetic relationship between Prod and ADG $(0.10[-0.26,0.38])$. In another paternal line of rabbits also selected for growth rate, the $\mathrm{r}_{\mathrm{g}}$ between Conc, Vol, and Prod with ADG was estimated to be $-0.09,0.36$, and 0.17 , respectively (Lavara et al., 2011). However, in that work, estimated $r_{g}$ had wide HPD95\%, making it difficult to draw unambiguous conclusions. Our estimates are in accordance with the phenotypic results obtained in an experiment of divergent selection for BW in rabbits in which the high line had greater sperm concentration and less ejaculate volume than the low line (Brun et al., 2006). Other estimates, reported in pigs, confirm that genetic correlations between growth and Vol, Conc, and Prod always had low magnitude (Oh et al., 2006; Wolft, 2009).

None of the genetic correlations between ADG and the other seminal traits analyzed in this work can be considered different from zero. Because of the null or very low magnitude of the genetic correlation between ADG and seminal traits, we would not expect selection for growth rate in this paternal line of rabbits to dam-
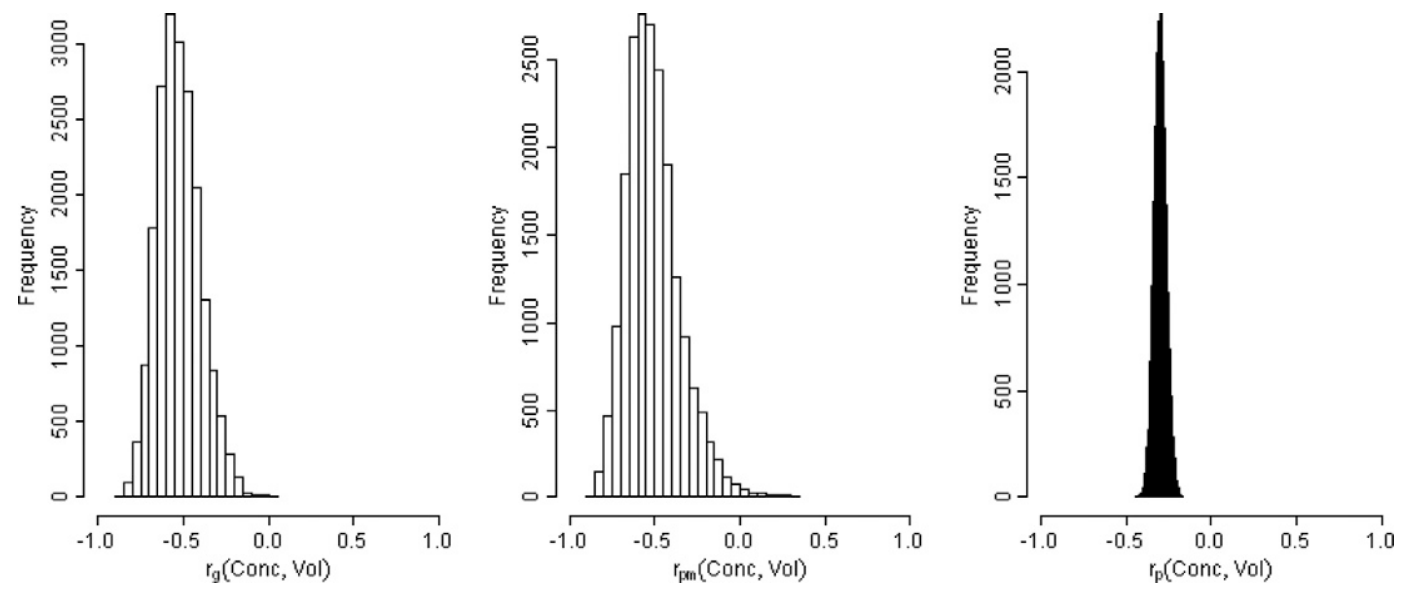

Figure 2. Estimated marginal posterior distributions of the genetic $\left[\mathrm{r}_{\mathrm{g}}().\right]$, male nonadditive genetic permanent environmental $\left[\mathrm{r}_{\mathrm{pm}}().\right]$, and phenotypic $\left[\mathrm{r}_{\mathrm{p}}().\right]$ correlation between average sperm concentration (Conc) and average volume (Vol) of the ejaculate on the day of collection. 
age semen production. In boars, Wolft (2009) reported low values of the genetic correlations between ADG and sperm motility, percentage of abnormal spermatozoa, and the composite trait, number of functional spermatozoa. No effect in Lib was encountered when 2 rabbit lines divergently selected for BW were compared in terms of rate of successful solicitations and in the average time until ejaculation (Brun et al., 2006).

All the correlations between permanent environmental effects for ADG and the seminal traits were of low magnitude (Figure 4) and a similar pattern was observed for the phenotypic correlations (Figure 5).

The correlation $\left(\mathbf{r}_{\mathbf{c o}}\right)$ between common birth litter effects for ADG and the seminal traits was very low, including zero in the $\mathrm{HPD}_{95 \%}$ except for Ca. For the last trait, the PM [HPD95\%] of $r_{\text {co }}$ was 0.37 [0.01, 0.81], suggesting that favorable litter effects for growth could be detrimental for the production of ejaculates free of Ca. However, the accuracy of this correlation estimate is very low because of the low magnitude of this vari-
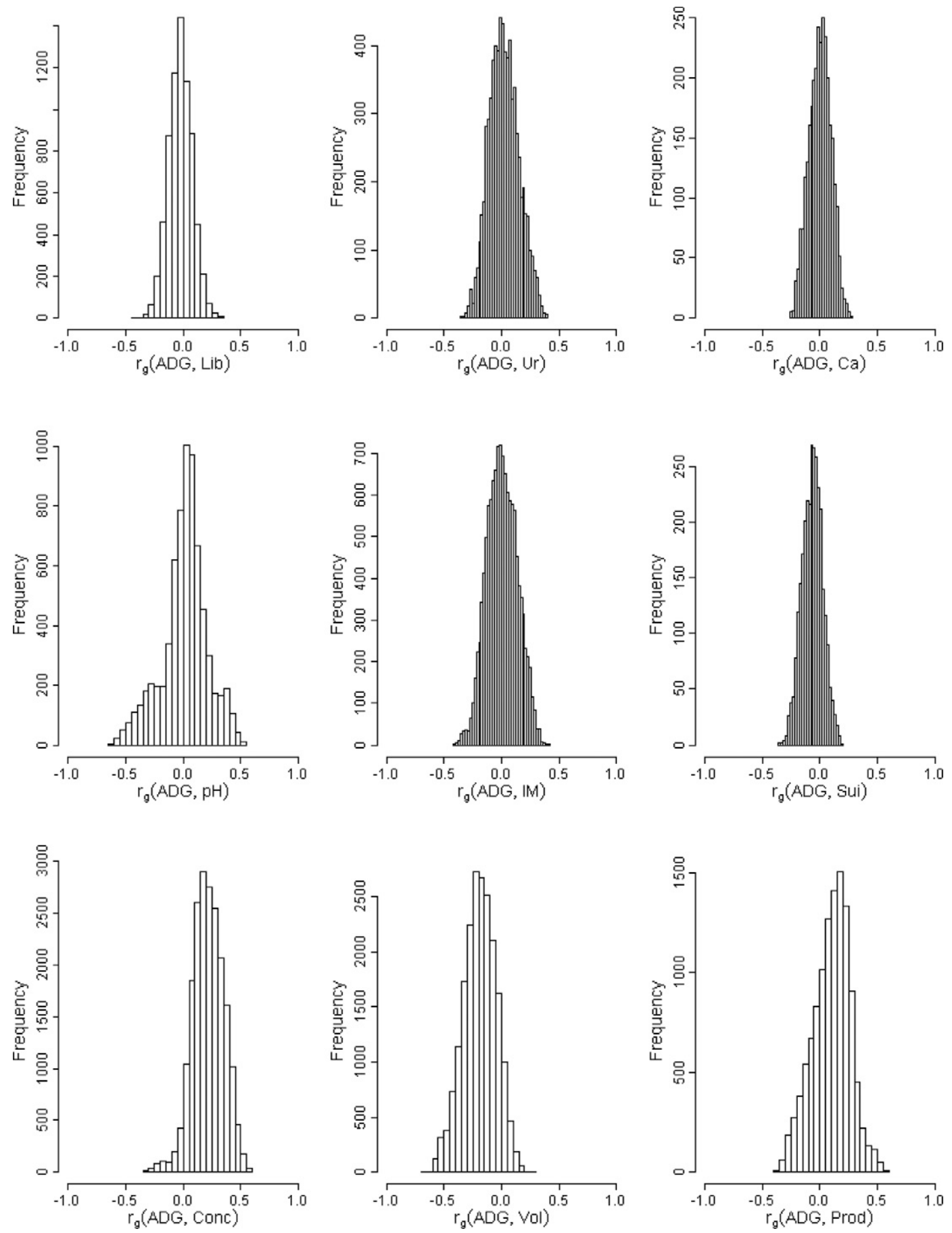

Figure 3. Estimated marginal posterior distributions of the genetic correlation $\left[\mathrm{r}_{\mathrm{g}}().\right]$ between ADG during the fattening period and the following seminal traits: male libido (Lib), presence of urine (Ur) and calcium carbonate deposits (Ca) in the ejaculate, semen pH, individual motility score (IM), and suitability for AI (Sui) of the ejaculate, average sperm concentration (Conc), average volume (Vol), and average sperm production per ejaculate (Prod). 

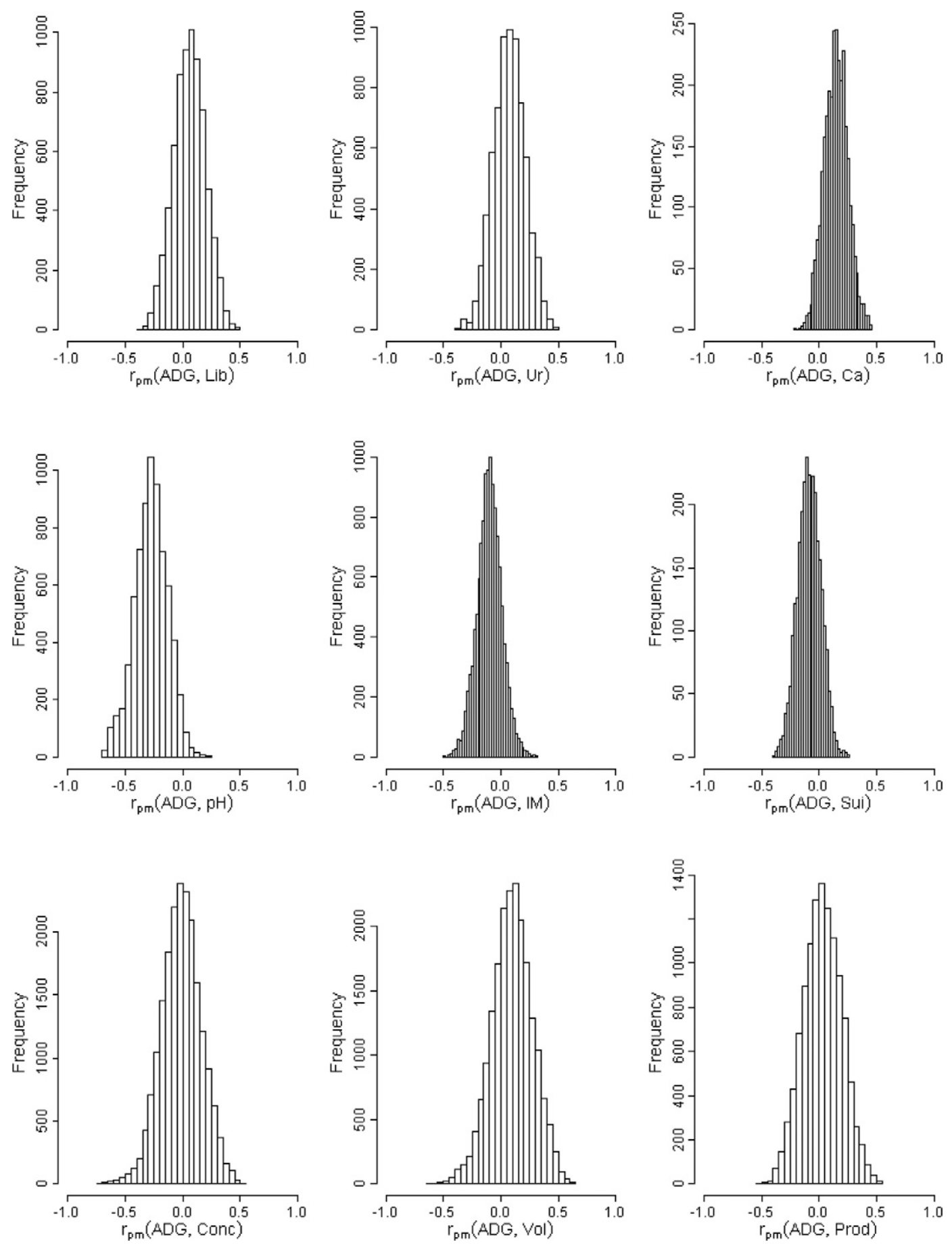

Figure 4. Estimated marginal posterior distributions of the male nonadditive genetic permanent environmental correlation $\left[\mathrm{r}_{\mathrm{pm}}().\right]$ between ADG during the fattening period and the following seminal traits: male libido (Lib), presence of urine (Ur) and calcium carbonate deposits (Ca) in the ejaculate, semen $\mathrm{pH}$, individual motility score (IM), and suitability for AI (Sui) of the ejaculate, average sperm concentration (Conc), average volume (Vol), and average sperm production per ejaculate (Prod).

ance component for $\mathrm{Ca}$. It is necessary to know the origin and causes of this trait to better understand the nature of this relationship.

Male libido and seminal traits related to the quality of the ejaculate ( $\mathrm{Ca}, \mathrm{Ur}, \mathrm{pH}$, and IM) seemed to be lowly heritable but repeatable. This indicates performance of bucks for seminal quality traits and libido in AI centers would be more strongly affected by management practices rather than genetic selection.

Moderate $\mathrm{h}^{2}$ were estimated for Conc, Vol, and Prod, suggesting the possibility of effectively selecting for increased sperm production in paternal lines. Because of the existence of a genetic antagonism between Conc and Vol, selecting for Prod would be of most interest because it is a composite trait that encompasses both traits. 

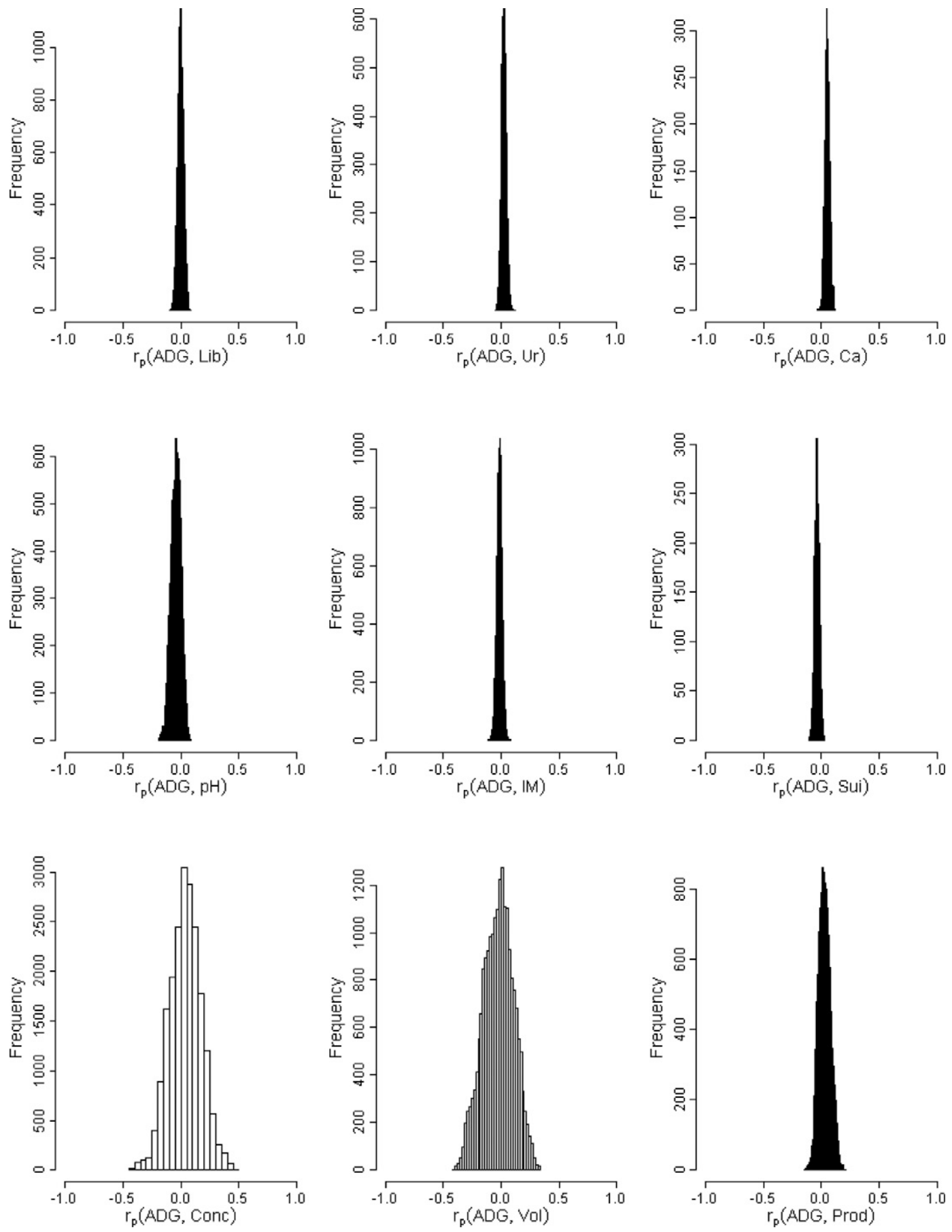

Figure 5. Estimated marginal posterior distributions of the phenotypic correlation $\left[\mathrm{r}_{\mathrm{p}}().\right]$ between ADG during the fattening period and the following seminal traits: male libido (Lib), presence of urine (Ur) and calcium carbonate deposits (Ca) in the ejaculate, semen pH, individual motility score (IM), and suitability for AI (Sui) of the ejaculate, average sperm concentration (Conc), average volume (Vol), and average sperm production per ejaculate (Prod). Phenotypic correlation between ADG and binary traits (Lib, Ur, Ca, and Sui) were based on the liability scale.

Selection for increasing ADG in paternal lines is not expected to have detrimental correlated effects on seminal traits involved in sperm production.

To improve the efficiency of bucks for AI dose production, it would be necessary to evaluate the expected response to selection applying different strategies and under different scenarios. It would be also required to establish the genetic relationship between semen production and quality traits (in order not to impair the fer- tilizing ability of AI doses), and to know the economic weights for these traits.

\section{LITERATURE CITED}

Alvariño, J. M. R. 2000. Reproductive performance of male rabbits. Proc. 7th World Rabbit Congr., Valencia, Spain A:13-35.

Baselga, M. 2004. Genetic improvement of meat rabbits. Programmes and diffusion. Proc. 8th World Rabbit Congr., Puebla, Mexico 1:1-13. 
Basso, B., S. Fritz, T. Druet, F. Guillaume, M. N. Rossignil, Y. Amigues, R. Gabriel, E. Sellem, L. Salas-Cortes, P. Humblot, and X. Druart. 2005. Estimation de paramètres génétiques et détection de QTL liés à des caractères de fertilité mâle, de production de semence et de qualité de la semence chez le taureau laitier. Pages 145-148 in Rencontre Recherche Ruminants, Paris, France.

Bencheikh, N. 1995. The effect of frequency of ejaculation on semen characteristics and sperm output in the rabbit. Ann. Zootech. 44:263-279.

Brun, J. M., A. Sanchez, R. Duzert, G. Saleil, and M. Theau-Clément. 2009. Paramètres génétiques des caractéristiques de la semence de lapin. 13èmes Journ. Rech. Cunicole, Le Mans, France. $11: 17-18$.

Brun, J. M., M. Theau-Clément, and G. Bolet. 2002a. Evidence for heterosis and maternal effects on rabbit semen characteristics. Anim. Res. 51:433-442.

Brun, J. M., M. Theau-Clément, and G. Bolet. 2002b. The relationship between rabbit semen characteristics and reproductive performance after artificial insemination. Anim. Reprod. Sci. 70:139-149.

Brun, J. M., M. Theau-Clément, J. Esparbié, J. Falières, G. Saleil, and C. Larzul. 2006. Semen production in two rabbit lines divergently selected for 63-d body weight. Theriogenology 66:2165-2172.

Castellini, C., and P. Lattaioli. 1999. Effect of motile sperms inseminated on reproductive performance of rabbit does. Anim. Reprod. Sci. 57:111-120.

Coffey, D. S. 1988. Androgen action and the sex accessory tissues. Pages 1081-119 in Physiology of Reproduction. E. Knobill and J. D. Neill, ed. Raven Press, New York, NY.

David, I., X. Druart, G. Lagriffoul, E. Manfredi, C. Robert-Granié, and L. Bodin. 2007. Genetic and environmental effects on semen traits in Lacaune and Manech tête rousse AI rams. Genet. Sel. Evol. 39:405-419.

Ducrocq, V., and P. Humblot. 1995. Genetic characteristics and evolution of semen production of young Normande bulls. Livest. Prod. Sci. 41:1-10.

Falconer, D. S. 1965. The inheritance of liability to certain diseases, estimated from the incidence among relatives. Ann. Hum. Genet. 29:51-76.

Flowers, W. L. 2008. Genetic and phenotypic variation in reproductive traits of AI boars. Theriogenology 70:1297-1303.

Furstoss, V., I. David, B. Leboeuf, P. Guillouet, P. Boue, and L. Bodin. 2009. Genetic and non-genetic parameters of several characteristics of production and semen quality in young bucks. Anim. Reprod. Sci. 110:25-36.

García-Tomás, M., J. Sanchez, O. Rafel, J. Ramon, and M. Plies. 2006a. Heterosis, direct and maternal genetic effects on semen quality traits of rabbits. Livest. Sci. 100:111-120.

García-Tomás, M., J. Sanchez, O. Rafel, J. Ramon, and M. Piles. 2006b. Reproductive performance of crossbred and purebred male rabbits. Livest. Sci. 104:233-243.

García-Tomás, M., J. Sanchez, O. Rafel, J. Ramon, and M. Piles. 2006c. Variability, repeatability and phenotypic relationships of several characteristics of production and semen quality in rabbit. Anim. Reprod. Sci. 93:88-100.

Geweke, J. 1992. Evaluating the accuracy of sampling-based approaches to the calculation of posterior moments. Oxford Univ. Press, Oxford, UK.

Geyer, C. J. 1992. Practical Markov chain Monte Carlo. Stat. Sci. $7: 473-511$

ITAVI. 2008. Gestion technico-économique des éleveurs de lapins de chair (programmes RENACEB et RENALAP) Résultats 2008.
Comité de pilotage de 10 de septembre 2009. http://www.itavi. asso.fr/economie/references/lapins.php.

Karoui, S., C. Díaz, M. Serrano, R. Cue, I. Celorrio, and M. J. Carabaño. 2011. Time trends, environmental factors and genetic basis of semen traits collected in Holstein bulls under commercial conditions. Anim. Reprod. Sci. 10.1016/j.anireprosci.2011.02.008.

Khalil, M. H., K. A. Al-Sobayil, A. M. Al-Saef, M. L. García, and M. Baselga. 2007. Genetic evaluation for semen characteristics in a crossbreeding project involving Saudi and Spanish V-line rabbits. Animal 1:923-928.

Knights, S. A., R. L. Baker, D. Gianola, and J. B. Gibb. 1984. Estimates of heritabilities and of genetic and phenotypic correlations among growth and reproductive traits in yearling Angus bulls. J. Anim. Sci. 58:887-893.

Larzul, C., and F. Gondret. 2005. Genetics of growth traits and meat quality in the rabbit. INRA Prod. Anim. 18:119-129.

Lavara, R., E. Moce, F. Lavara, M. P. V. de Castro, and J. S. Vicente. 2005. Do parameters of seminal quality correlate with the results of on-farm inseminations in rabbits? Theriogenology 64:1130-1141.

Lavara, R., J. S. Vicente, and M. Baselga. 2011. Genetic parameter estimates for semen production traits and growth rate of a paternal rabbit line. J. Anim. Breed. Genet. 128:44-51.

Legarra, A., L. Varona, and E. López de Maturana. 2008. TM Threshold Model. Accessed Oct. 31, 2008. http://snp.toulouse.inra. $\mathrm{fr} / \sim$ alegarra/manualtm.pdf.

More O'Ferrall, G. J., and T. N. Meacham. 1968. Relationship between $\mathrm{pH}$, other semen traits and fertility in rabbits. VI Congr. Intern. Reprod. Anim. Insem. Artif., Paris. 2:1279-1281.

Morrell, J. M. 1995. Artificial insemination in rabbits. Br. Vet. J. 151:477-488.

Moura, A. S., M. Kaps, D. W. Vogt, and W. R. Lamberson. 1997. Two-way selection for daily gain and feed conversion in a composite rabbit population. J. Anim. Sci. 75:2344-2349.

Oh, S. H., M. T. See, T. E. Long, and J. M. Galvin. 2006. Estimates of genetic correlations between production and semen traits in boar. Asian-australas. J. Anim. Sci. 19:160-164.

Panella, F., C. Castellini, and E. Facchin. 1994. Heritability of some male reproductive traits in rabbit. Options Mediterr. 8:279-283.

Piles, M., E. A. Gomez, O. Rafel, J. Ramon, and A. Blasco. 2004. Elliptical selection experiment for the estimation of genetic parameters of the growth rate and feed conversion ratio in rabbits. J. Anim. Sci. 82:654-660.

Raftery, A. E., and S. Lewis, ed. 1992. How many iterations in the Gibbs sampler? Bayesian statistics 4. Oxford Univ. Press, New York, NY

Rege, J. E. O., F. Toe, E. Mukasa-Mugerwa, S. Tembely, D. Anindo, R. L. Baker, and A. Lahlou-Kassi. 2000. Reproductive characteristics of Ethiopian highland sheep: II. Genetic parameters of semen characteristics and their relationships with testicular measurements in ram lambs. Small Rumin. Res. 37:173-187.

Robinson, J. A. B., and M. M. Buhr. 2005. Impact of genetic selection on management of boar replacement. Theriogenology 63:668-678.

Roca, J., S. Martinez, J. M. Vazquez, X. Lucas, I. Parrilla, and E. A. Martinez. 2000. Viability and fertility of rabbit spermatozoa diluted in Tris-buffer extenders and stored at 15 degrees C. Anim. Reprod. Sci. 64:103-112.

Rosell, J. M., and L. F. de la Fuente. 2009. Culling and mortality in breeding rabbits. Prev. Vet. Med. 88:120-127.

Smital, J., J. Wolf, and L. L. De Sousa. 2005. Estimation of genetic parameters of semen characteristics and reproductive traits in AI boars. Anim. Reprod. Sci. 86:119-130. 
Sorensen, D., and D. Gianola. 2002. Likelihood, Bayesian, and MCMC Methods in Quantitative Genetics. Springer Science and Business Media, LLC, New York, NY.

Theau-Clément, M., J. M. Brun, E. Sabbioni, C. Castellini, T. Renieri, U. Besenfelder, J. Falieres, J. Esparbie, and G. Saleil. 2003. Comparaison de la production spermatique de trois souches de lapins: Moyennes et variabilités. 10èmes Journ. Rech. Cunicole, Paris, France. 81-84.

Theau-Clément, M., and J. Falières. 2005. Evaluation de la concentration de semence de lapins selon 2 méthodes: Hématimètre et nucleocounter sp100. Pages 95-99 in Proc. 11èmes Journées de la Recherche Cunicole, Paris, France.

Theau-Clément, M., A. Sanchez, and R. Duzert. 2009. Etude de facteurs de variation de la production spermatique chez le lapin. 13èmes Journées de la Recherche Cunicole, Le Mans, France. Tusell, L., A. Legarra, M. García-Tomás, O. Rafel, J. Ramon, and M. Piles. 2011. Different ways to model biological relationships between fertility and the $\mathrm{pH}$ of the semen in rabbits. J. Anim. Sci. 89:1294-1303.

Vogt, D. W. 1979. Selection experiment with domestic rabbits. J. Hered. 70:421-422.

Wolf, J., and J. Smital. 2009. Quantification of factors affecting semen traits in artificial insemination boars from animal model analyses. J. Anim. Sci. 87:1620-1627.

Wolft, J. 2009. Genetic correlations between production and semen traits in pig. Animal 3:1094-1099.

Wright, S. 1934. An analysis of variability in number of digits in an inbred strain of guinea pigs. Genetics 19:0506-0536. 
References

This article cites 36 articles, 6 of which you can access for free at: http://www.journalofanimalscience.org/content/90/5/1385\#BIBL 